\title{
CFD-AIDED OPTIMIZATION OF CUSTOMER-SPECIFIC TANK SYSTEMS USING AN INNOVATIVE LABYRINTH DEAERATOR
}

\author{
Karl Wartlick*, Matthias Baumann, Andras Veres, Roman Weidemann \\ ARGO-HYTOS GmbH, Industriestrasse 9, 76703 Kraichtal, Germany \\ * Corresponding author: Tel.: +49 0725076 -0; E-mail address: K.Wartlick@argo-hytos.com
}

\section{ABSTRACT}

This paper introduces the comprehensive approach of ARGO-HYTOS in developing and optimizing hydraulic tanks. Starting with a detailed analysis of the application, the tank design was optimized and an innovative deaerator was developed. In a first step, various Computational Fluid Dynamics (CFD) -based analyzing methods are presented, which are used to support the optimization process of tank development with regard to complex flow conditions and unexpected influences. The main topic of this paper is the introduction of an innovative labyrinth deaerator, causing coalescence of air bubbles, slower subsequent flow conditions and finally a better deaeration. A further focus is on a customized deaeration test rig, which is used to validate improved components and tank designs on the one hand and to learn more about the complex deaeration effects on the other hand.

With this comprehensive optimization approach and the innovative, compact and patented labyrinth deaerator, the size of the tank and the amount of oil can be reduced to a minimum, without impairing air separation, but on the contrary, even improving the air separation behavior.

Keywords: CFD, Tank optimization, Hydraulik Tank, Deaeration

\section{INTRODUCTION}

Increasingly complex construction space, the need for harmonization, integration of functions, as well as the pursuit of efficiency and a minimum usage of resources - all of these factors keep challenging the development of hydraulic systems. In order to meet these requirements and the fundamental objective of cost reduction, as well, reducing tank volume seems to be a main target for redesigns or new developments. However, this method bears a risk. The reduction of oil and tank volume lead to less heat exchange, as well as to increasing fluid aeration, both of which accelerate the oil aging process and cause a loss of performance, efficiency and component durability. Without a detailed analysis, optimization and validation of the tank system, an initial cost reduction may be negated by unforeseeable secondary costs and risks. To compensate for the shortened oil dwell time, an optimized tank volume utilization and a fast oil deaeration is vital.

The optimization of hydraulic oil reservoirs is sparsely treated in basic literature. The remarks on this issue are limited to design advice without further explanations. Technical literature merely deals with stationary applications, the examples being welded steel boxes across the board [1], [2], [3].

The recommendations and advice given regard deceleration of the flow, such as keeping a maximum distance between return and suction ports, separating them by position as well as geometrically by baffle, and avoiding abrupt changes of flow cross sections. Another advice is to make sure that the minimum distance to walls and oil surface is always observed, as this leads to deceleration and less turbulences, which are good conditions for a better deaeration behavior. Therefore, these tips are applicable to all reservoirs, whether they are stationary or mobile, made from steel or polymers, and independent of the manufacturing process. However, these recommendations are component-based and aim to improve flow conditions for each component, not the entire system. That optimizing individual components also improves the tank as a system is only implied. What is more, the interrelation of the components as a system and their influence on the system flow can only be abstracted for less complex geometries with a small amount of elements, such as a rectangular steel box. 
Especially in mobile applications, the shape, weight and integration of functions are more important. For example, the weight of a stationary tank has no impact on the efficiency of a hydraulic press but it would have a major effect on mobile machinery. Tank designs in mobile applications are usually more complex, which makes a comprehensive consideration of a hydraulic tank system very challenging.

In this paper, the possibilities of supporting the optimization of hydraulic tanks by means of computational fluid dynamics within the development process is discussed, as well as the opportunity to improve deaeration behavior by applying a new type of labyrinth deaerator.

\section{HOW CFD CAN SUPPORT TANK DEVELOPMENT AND OPTIMIZATION}

With their experience in hydraulic systems - beyond their main expertise in filtration, valves and applications - ARGO-HYTOS also develop and manufacture hydraulic tanks. For quantities of less than hundred or several thousand pieces, the company offers the Hybrid Integrated Tank (HIT) technology or proprietary injectionmolded solutions.

By using Computational Fluid Dynamics (CFD), any complex geometry and constellation can be mathematically modeled. Loaded with operating conditions, the system can be simulated and the results can be used to assess its behavior. CFD is used as a tool to analyze the oil volume in order to optimize the tank geometry. In addition, dead zones, vortexes and unintended increased velocities within internal flow channels formed by secondary streams and fluid movements can be detected. In the same way, the simulation helps to evaluate the deaeration behavior of a newly designed tank; being aware of the flow conditions is absolutely beneficial. Even small modifications in the geometry, such as unfavorably placed cutouts, rips, slants or other shapes obtruding the stream can change the flow conditions. With CFD simulation, the changes can be identified and their influence analyzed.

To implement the optimization process early on, the first model of the tank concept is reviewed based on the results of the CFD simulation. With the approach to regard a steady state one-phase flow under maximum conditions, it is the goal to get quick valid results and to evaluate whether the tank concept is going in the right direction.
Therefore, several post-processing features are considered. Streamlines visualize the paths of an arbitrary amount of fluid and give a general overview of the total flow movement. The color of the lines provides additional information, such as velocity or dwell time or any other physical parameters the simulation has calculated. By extracting bubble tracks from the simulation, illustrated in Figure 1, an initial statement on the tank's deaeration behavior can be made. In this context, similar to the streamlines, the paths of bubbles are shown according to their density and size. Depending on the simulation's boundary conditions, bubbles can be evaluated as deaerated by reaching the oil level or remaining in the system when they pass the suction outlets. In addition, a look at the pressure distribution of the oil level indicates possible vertical movements. Supported by two-dimensional velocity plots, predictions concerning potential optimization areas can be made and considered in further development. In a subsequent step, by comparing the simulation results of an optimized design with the former design, the improvements can be verified or previously undetected negative effects can be figured out and avoided in an additional development loop.

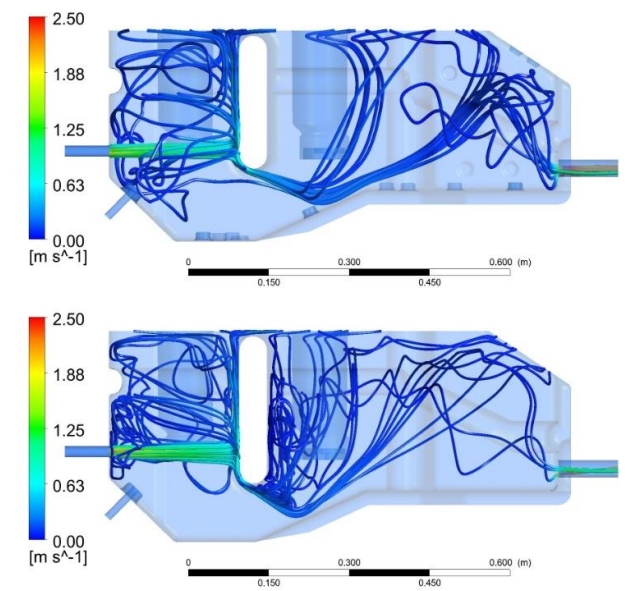

Figure 1: Simulated bubble tracks of a polymer tank with a shorter (upper fig.) and an extended baffle (lower fig.)

In the following example, this process led to a successful revision of an existing steel tank. The result is a new, optimized polymer construction with benefits in costs and deaeration, shown in Figure 2, under less oil volume. 


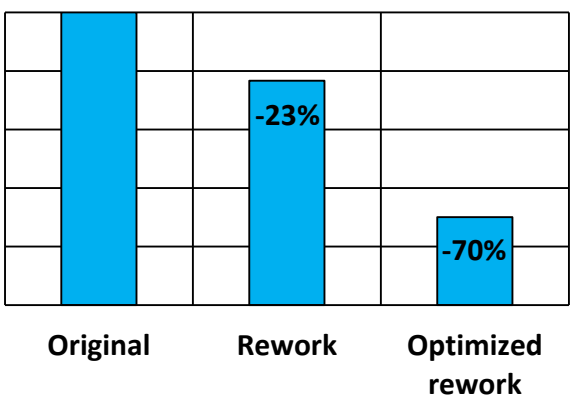

Figure 2: Comparison of the remaining dissolved bubbles depending on the stage of development

After analyzing the initial state, the concept was newly arranged with respect to the tank advice given in literature and the polymer design information. The review with the CFD simulation showed an obviously better deaeration behavior. Concerning the possibility to have major impact with little changes in geometry, the extension of the baffle wall led to a better separation between return and suction area, resulting in even better deaeration, as shown in Figure 2. Previously, the main return was not distributed but unfortunately deflected by the baffle and a subsequent slope. That led to a nearly unrestricted bypass channel to the outlet. However, this has been avoided during the concept phase without any major delay by using CFD to analyze, evaluate and decide how to move on.

On one hand, the potential spots for optimization without disturbing the tank functions can be identified before a redesign is executed; on the other hand, the new design can be analyzed and compared to the former shape. Thus, the process of new development, as well as rework, can be supported by the experience of ARGO-HYTOS to meet tougher requirements while improving functionality.

While these methods are conducted to improve the flow conditions with the aim of achieving better deaeration, developments by not only modifying the oil but also the air are followed up.

\section{LABYRINTH DEAERATOR}

Once the limits of tank optimization and tank size reduction with the help of CFD and design changes are reached, an innovative labyrinth de- aerator (Figure 3) offers new possibilities and degrees of freedom to further optimize or to further reduce the size of tank concepts, without impairing air separation within the tank. The deaerator was developed with the aim of combining it with return filters, while making sure that this combination requires only slightly more space. Due to this reason, it is small and compact; it can be adapted to fit current return filter ranges and it can be integrated into virtually all existing, as well as newly designed tank systems without any problems. With this - in addition to various functions that can already be integrated into the tank (HIT concept) -another essential feature is available, which allows tank solutions to be successful even if installation space is limited.

Comparing the labyrinth deaerator with alternative solutions and approaches available on the market, among others, cyclones [4] can be found. With these, the idea is to create a centrifugal field induced by rotational flow, in which phase separation or an accumulation of air bubbles occur. At first glance, this is an obvious approach. However, the flow must first be accelerated to high velocities, which results in an additional pressure loss in the return line that cannot be disregarded. If the flow is accelerated too much, this will also lead to elongational flows and, in conjunction with turbulences, to air bubble disintegration. This, in turn, counteracts the actual goal of air separation. What is more, it is neither easy nor cost-efficient to adjust a cyclone to larger flow ranges or operating states. The labyrinth deaerator has no such disadvantages. It presents a very stable deaeration behavior across a wide range of operating conditions, while keeping differential pressure at a negligible level.

Another approach in the market is air discharge into the tank directly via openings in the bowl of a return filter; among other things, the air can be discharged closer to the oil surface, thus shortening the air bubbles" way to the surface. However, in mobile hydraulic applications, especially, the oil volume may vary considerably depending on the given operating condition. If the openings are above oil level, this is extremely counterproductive and with high flow rates, in particular, more air enters the hydraulic system than is separated. In contrast, the labyrinth deaerator can always be reliably mounted below oil level and, if required, it can be placed even lower in the tank with the help of a tube extension. 


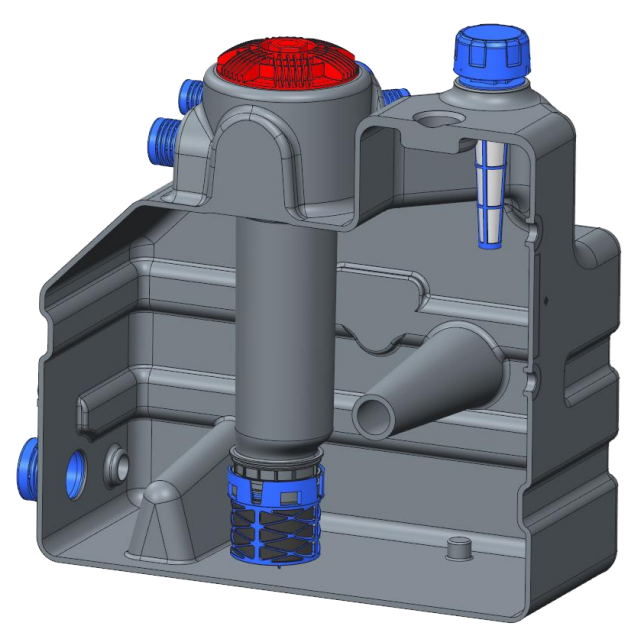

Figure 3: The labyrinth deaerator integrated into a Hybrid Integrated Tank (HIT)

\subsection{Function}

The key idea on which the labyrinth deaerator is based and for which a patent application has been registered is to have the air bubbles pass through a 3D labyrinth structure before they enter the tank; within this 3D labyrinth structure, smaller air bubbles can merge and form into larger bubbles. Moreover, the deaerator reduces the air entrance velocity into the tank, thus acting as a diffusor at the same time. Due to the reduced flow velocities in the tank, there is less turbulence, which might prevent air bubbles from ascending. Figure 4 is a simplified representation of the function of the labyrinth deaerator.

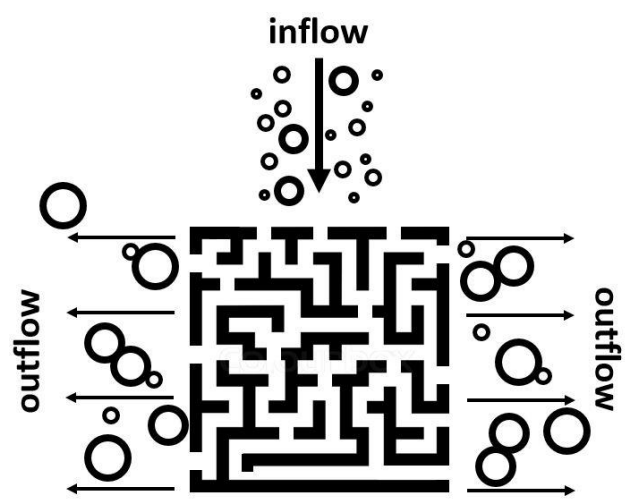

Figure 4: Functional principle of the labyrinth deaerator

The air bubbles entering the deaerator are constantly being redistributed and redirected with the flow through the material structure. This significantly increases the likelihood of air bubble collisions and the coalescence of air bubbles with it.

\subsection{Test results}

The labyrinth deaerator was developed and tested for a wide range of conditions to ensure that it works well in the most diverse operating conditions. In the process of development, a multitude of tests were performed with the deaerator, which were based on and performed in comparison with a reference system using a return filter without labyrinth deaerator. The following parameters were examined, among others:

- temperature (oil, viscosity)

- flow rate

- air content and type of air injection

- dwell time in the tank $(15-35 \mathrm{sec})$

- tank size reduction of up to $30 \%$

In principle, two types of air injection were selected for these tests; the first type was air injection in blasts, as it might occur in practice after a filter element removal (adding a defined amount of air within 30 seconds). The second way was to add air over a longer period (15 minutes) in a lower concentration.

It is especially interesting that the labyrinth deaerator can substantially contribute to realizing a tank size reduction, without this having any negative effect on the air separation qualities of the tank.

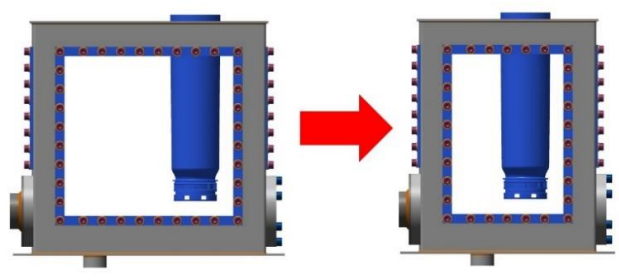

Figure 5: Test rig tank before and after 30\% reduction

As can be seen in Figure 5, the test rig tank was narrowed down in one dimension and the oil quantity was adjusted accordingly. Figure 6 shows the measuring results for the tank reduced by $30 \%$ in size, with labyrinth deaerator, compared with the reference system without size reduction and without labyrinth deaerator. The tests were performed with an air injection of 3\% (over a period of 15 minutes) at $45^{\circ} \mathrm{C}$ and at $75 \%$ of 
nominal flow rate of the filter. What can be seen is that the air concentration decreases much faster with the deaerator once air injection ends than it does in the reference system without the deaerator - this even though tank size and oil quantity were significantly reduced.

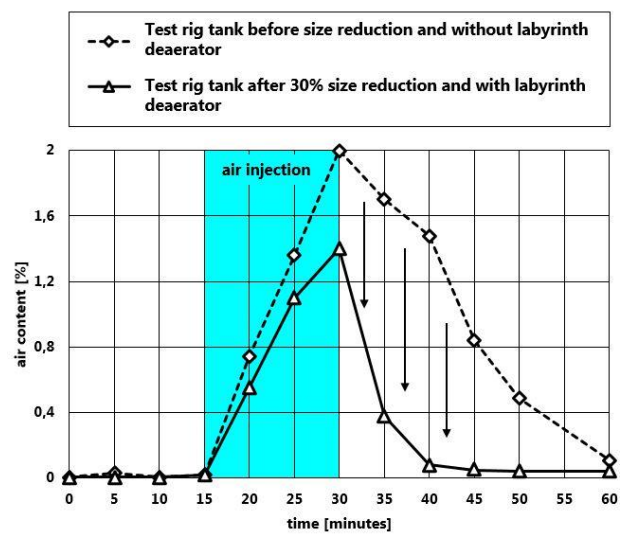

Figure 6: Deaeration of the test rig tank with return filter before and after $30 \%$ reduction

It is also quite interesting how the labyrinth deaerator performs in comparison with the solutions by competitors mentioned above. Comparative tests have definitively confirmed that the labyrinth deaerator works better than all other solutions tested. Figure 7 shows a comparative test.

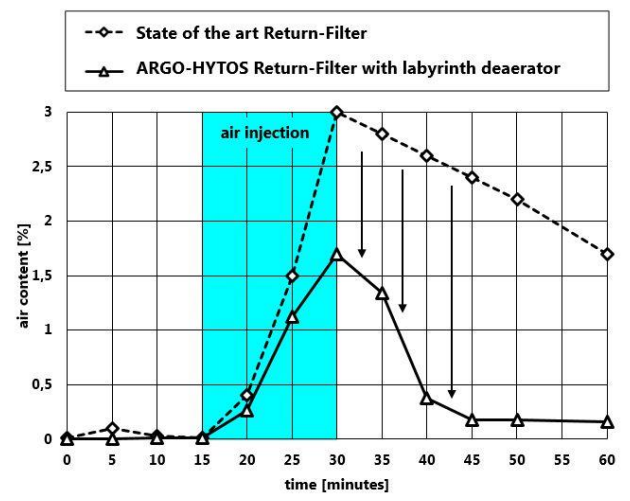

Figure 7: Deaeration of a state of the art return filter and an ARGO-HYTOS return filter with labyrinth deaerator

A state of the art return filter (which is supposedly optimized for air separation, in particular) was tested against an ARGO-HYTOS return filter with labyrinth deaerator. The test was performed at nominal flow rate with $3 \%$ air injection (over a period of 15 minutes). In this test, the labyrinth deaerator could clearly demonstrate its virtues and achieved very good results. The advantages could be noticed already during air injection - the maximum concentration at the end of air injection was considerably lower than it was in tests of the solutions offered by the competition.

\section{TEST RIG}

For development of the labyrinth deaerator but also for other projects a multifunctional test rig was built. The test rig is supposed to make extensive and comprehensive testing and assessment of the air separation performance in hydraulic tanks possible. Achieving a high level of reproducibility was one of the most important requirements. Figure 8 shows the test rig's schematic.

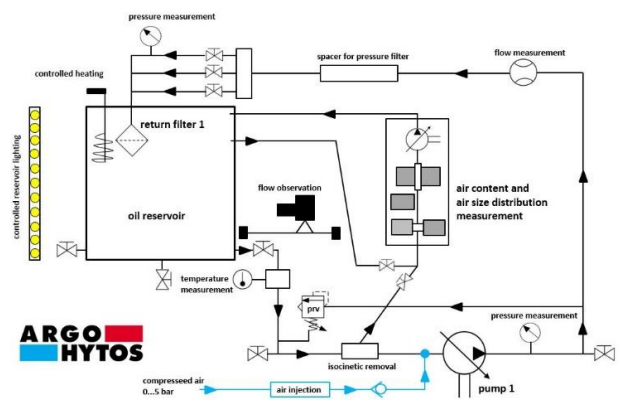

Figure 8: Schematic diagram of the deaeration test rig

Multifunctional means that the test rig can be converted quickly to test and compare various tank concepts, tank size reductions, filters or other components/installations and devices in tanks. Among other things, the following is possible:

- reduce test rig tank size by up to $30 \%$

- tank exchange (customized tank)

- filter exchange (size, fineness, ...)

- several return line connections

- pump for a large flow range

Another objective of building a multifunctional test rig was to be able to validate CFD simulation results. At the same time, the test results and sensor data of the test rig also help in setting useful parameters for the CFD simulation. This results in improved and more realistic CFD simulation, especially when considering air separation. 


\section{SENSOR AND MEASURING TECHNOLOGY}

It is a challenge to detect air content and air bubbles in oil by means of sensor technology [5]. For this purpose not only different sensors are used and measuring solutions as well as evaluation methods to better assess and understand the problem ,air in oil" in the test rig are developed. In addition to measurements and evaluation of number and size of the air bubbles, the air content can also be measured continuously, or it can be determined based on measuring data. The measuring technology for determining air content and air bubble size distribution integrated in the test rig can be used independent of the test rig, as well, for on-site measurements in mobile applications at the customer's (see Figure $9 \&$ Figure 10).

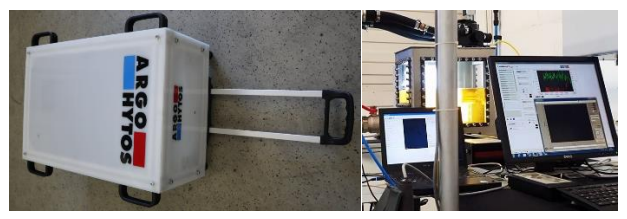

Figure 9: Measurement system for air content and air size distribution

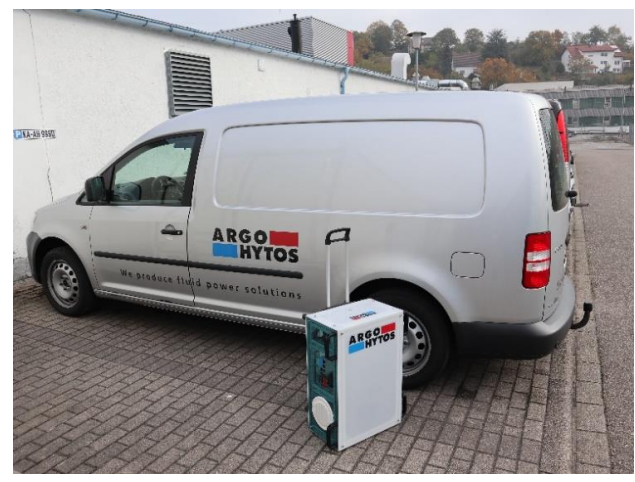

Figure 10: On-site measurement system

On-site measurements can help to find useful optimization approaches and to verify them not only in a simulation but in the actual machine, as well.

With the help of the evaluation method, valuable information on air content, separation times, separation efficiency/rate and general air separation performance based on the size and number of air bubbles can be gained. Figure 11, for example, shows a three-dimensional visualization of deaeration.

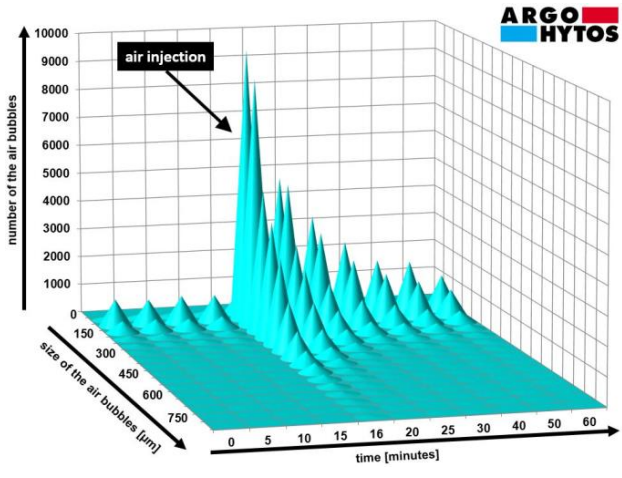

Figure 11: 3D diagram of the deaeration of a return filter

Figure 12 presents a measured bubble size distribution and a simulated distribution adapted to it. In this way, much better application- and customer-specific CFD simulations can be performed.
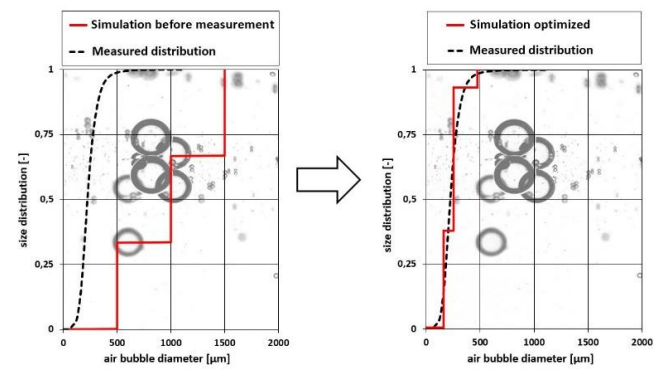

Figure 12: Adapted bubble size classes for more realistic CFD calculation based on measurement data

\section{CONCLUSION AND OUTLOOK}

Within the framework of CFD simulation, the issue ,air in hydraulics", development of an innovative deaerator and building of a multifunctional test rig to validate this deaerator have been addressed, among other things. The test rig contains sensor and measuring technology for analysis purposes that can also be used at the customer's location. What is more, ARGO-HYTOS manufacture hybrid integrated tank systems (HIT) themselves, and the experience and knowledge gained are taken into account in the development and optimization phases of each new tank system. The company is thus well-equipped to offer comprehensive and competent support in optimizing 
tank systems according to customers' specific needs.

Air in hydraulic fluids will remain an important and interesting issue. Whether it is about improving simulation options, finding new approaches to tank optimization, or further enhancing deaeration concepts, better solutions will be continued to come up with here, in close cooperation with customers.

\section{REFERENCES}

[1] D. Findeisen und S. Helduser, Ölhydraulik Handbuch der hydraulischen Antriebe und Steuerungen, Berlin Heidelberg: Springer Vieweg, 2015.

[2] H. J. Matthies und K. T. Renius, Einführung in die Ölhydraulik, Wiesbaden: Vieweg+Teubner Verlag, 2011.

[3] D. Will und N. Gebhardt, Hydraulik Grundlagen, Komponenten, Schaltungen, Berlin Heidelberg: Springer-Verlag, 2011.

[4] S. Sakama, Y. Tanaka, H. Higashi, H. Goto und R. Suzuki, „Air Bubble Separation and Elimination from Working Fluids for Performance Improvement of Hydraulic Systems, " in IFPE 2014, Las Vegas, USA, 2014.

[5] K. Schrank, H. Murrenhoff und C. Stammen, „Investigation of different methods to measure the entrained air content in hydraulic oils," in ASME/BATH 2014 Symposium on Fluid Power \& Motion Control, Bath, United Kingdom, 2014. 